\title{
A CULTURA DA VIOLÊNCIA E O PROCESSO FORMATIVO PARA A EXPERIÊNCIA: NOTAS A PARTIR DA REFLEXÃO SOBRE A EDUCAÇÃO APÓS AUSCHWITZ
}

\author{
Estelamaris Brant Scarel \\ Pontifícia Universidade Católica de Goiás (PUC-GO), Goiânia, \\ Goiás, Brasil
}

\begin{abstract}
Resumo: Este texto, apoiando-se em alguns fundamentos da Teoria Crítica da Sociedade, especialmente, de Theodor Adorno, procura elaborar, em primeiro lugar, uma reflexão sobre a violência na realidade contemporânea, e, em segundo e último lugar, discutir sobre a relevância da experiência para a formação humana, visando ao estabelecimento do confronto ao extremismo possibilitado pelo advento de Auschwitz.
\end{abstract}

Palavras-chave: Contemporaneidade. Violência. Educação. Experiência. Auschwitz.

\section{O CONTEXTO CONTEMPORÂNEO SOB A INSÍGNIA DA VIOLÊNCIA}

A leitura do segundo capítulo da obra Os afogados e os sobreviventes: os delitos, os castigos, as penas, as impunidades (2016), do sobrevivente de Auschwitz Primo Levi, denominado de "A zona cinzenta", é de grande importância por dois motivos. O primeiro deles diz respeito à percepção do quanto uma cultura pode se degradar diante da simplificação do mal. Antes de seguir-se no raciocínio, é preciso que se faça um parêntese para explicitar qual é o sentido de cultura que se atribui a esta reflexão. Trata-se do mesmo significado dado a esse vocábulo por Adorno e Horkheimer, ao apoiarem-se 
em um texto de Freud sob o título de "O futuro de uma ilusão" (1927), o qual é assim apreendido por esses frankfurtianos:

A "cultura humana" - entendendo por isto toda a ascensão ocorrida na vida humana desde as suas condições animais e pela qual se distingue da vida dos animais, e abstendo-me da insípida distinção entre cultura e civilização - mostra claramente dois aspectos a quem a observa. Por um lado, abrange todo o saber e capacidade que os homens adquiriram para dominar as forças da natureza e obter os bens que satisfazem as necessidades humanas; e, por outro lado, todas as instituições necessárias para reger as relações dos homens entre si e, mormente, a distribuição dos bens obtidos. Estes dois sentidos da cultura não são mutuamente independentes, primeiro, porque as relações recíprocas dos homens se modificam profundamente, na medida em que a satisfação dos impulsos se torna possível através dos bens disponíveis; segundo, porque o próprio indivíduo humano pode estabelecer com outro uma relação de homem a coisa, quando o outro utiliza sua força de trabalho ou é adotado como objeto sexual; terceiro, porque cada indivíduo é, potencialmente, um inimigo virtual dessa cultura que, entretanto, há de ser um interesse humano universal (ADORNO; HORKHEIMER, 1978, p. 97).

A elucidação desse termo, talvez, seja mais significativa para o que se vai apontar como segunda motivação, pois ela diz respeito à incapacidade de as pessoas resistirem à cooptação e colaborarem com a perpetuação de um poder extremamente violento e desumanizador, mediante a identificação com o opressor. Na perspectiva de Levi (2016), essa atitude "mimética" exercida pelos colaboradores, isto é, pelos "kapos", teve uma repercussão e uma gravidade inimagináveis, em virtude de ela conduzir a vida dos cooptados a uma "zona cinzenta".

Ter concebido e organizado os esquadrões foi o delito mais demoníaco do nacional-socialismo. Por trás do aspecto pragmático (fazer economia de homens válidos, impor a outros as tarefas mais atrozes) se podem ver outros mais sutis. Através dessa instituição, tentava-se transferir para outrem, e precisamente para as vítimas, o peso do crime, de tal sorte que para o consolo delas não ficasse nem a consciência de ser inocente [...] Nós, o povo dos Senhores, somos quem os destrói, mas vocês não são melhores do que nós; se quisermos, e o queremos, nós somos capazes de destruir não só seus corpos mas também suas almas, tal como destruímos as nossas (LEVI, 2016, p. 41).

Todavia, esses comportamentos eivados de frieza e estarrecedores não estão vinculados apenas a elementos objetivos, isto é, racionais. Eles, também, relacionam-se à dimensão subjetiva do indivíduo, ou seja, ao âmbito das suas profundezas inconscientes, minando seus corpos e suas 
mentes não apenas no contexto acima exposto por Levi (2016), mas, também, na sociedade contemporânea, conduzindo as pessoas, de uma maneira alarmante, a vivenciarem uma realidade falsa, porquanto elas sedimentaram no esquecimento essa experiência extrema e degradante do gênero humano.

Por isso, as reflexões realizadas por Adorno dos anos $1950 \mathrm{em}$ diante tornaram-se imperativas no sentido de se travar o combate contra o esquecimento ao horror provocado pela cultura da imitação ou, de outra maneira, pela cultura da conivência com os algozes, a qual, implacavelmente, conduziu seus adeptos à alienação e, também, à destruição. "Quem se coloca a favor da cultura radicalmente culpada e mesquinha transforma-se em colaborador, enquanto quem se recusa à cultura fomenta imediatamente a barbárie com a qual a cultura se revela" (ADORNO, 2009, p. 304).

É exatamente contra esse estado de barbarização, isto é, contra quaisquer formas de extremismos, que as preocupações desse frankfurtiano recaem. Uma primeira manifestação dessas preocupações por parte de Adorno ocorreu por meio da conferência intitulada "O que significa elaborar o passado", proferida no Conselho de Coordenação para a Colaboração Cristã-Judaica, em 1959, a qual foi publicada posteriormente em "Relato sobre a Conferência de Educadores", na Wiesbaden, em novembro de 1959, e em uma obra de Adorno denominada Eingriffe (Intervenções), em 1963, sendo transmitida também pela rádio de Hessen em 7 de fevereiro de 1960. Uma segunda ocasião em que o autor expressa seus receios nesse sentido é quando ele profere a palestra"Educação após Auschwitz" - que será objeto de discussão na próxima seção deste texto -, transmitida pela rádio de Hessen, em 18 de abril de 1965, e publicada em Zum Bildungsbegriff der Gegenwart, em 1967, e, futuramente, em 1969, em Stichworte (Motes).

Verifica-se que em ambas as conferências é recorrente a apreensão de Adorno (1995a) com os destinos da humanidade em face da resistência por parte dos sujeitos à "elaboração do passado". Aliás, este é um tema que já se fazia presente na obra Dialética do Esclarecimento (1985), produzida por Adorno e Horkheimer entre 1941-1947. No prefácio, os filósofos declaram o seguinte.

Se o esclarecimento não acolhe dentro de si a reflexão sobre esse elemento regressivo, ele está selando seu próprio destino. Abandonando a seus inimigos a reflexão sobre o elemento destrutivo do progresso, o pensamento cegamente pragmatizado perde seu caráter superador e, por isso, também sua relação com a verdade (ADORNO; HORKHEIMER, 1985, p. 13). 
A pertinência e a relevância desta afirmação não residem somente na premência de se exercitar a rememoração, mas, sobretudo, recaem na urgência de o sujeito voltar-se para si mesmo por meio da autorreflexão critica. Este é o sentido atribuído por Adorno (1995b), a partir de Kant (1996), ao giro copernicano, a fim de romper com o encantamento, ou, de outra maneira, com a idealização, mediante o exercício da experiência.

O esforço do conhecimento é, preponderantemente, a destruição de seu esforço habitual, a violência contra o objeto. $\mathrm{O}$ ato aproxima-se de seu conhecimento quando o sujeito rasga o véu que tece ao redor do objeto. Ele só é capaz disso quando, com passividade isenta de angústia, se confia à sua própria experiência (ADORNO, 1995b, p. 194).

Na sua concepção, somente por meio dessa disposição para o exercício da autorreflexão crítica, ou seja, para a experiência, é que o sujeito irá munir-se da capacidade de se conscientizar acerca da necessidade de se livrar dos mitos que o enredaram nas amarras "[...] desses mecanismos de repressão e dessas formações reativas que deformam nas próprias pessoas sua aptidão à experiência" (ADORNO, 1995a, p. 150).

Não obstante essa tese contundente, verifica-se que, na realidade contemporânea, os mecanismos de violência e de extremismos têm se estendido por diversos aspectos e dimensões da vida humana, seja no tocante à ideologia, seja com referência à intolerância ao credo, à raça, ou, ainda, a quaisquer escolhas de ordem pessoal, denotando que os exemplos negativos anteriores não contribuíram para que as pessoas se livrassem dos tabus e das teias de barbarização que as oprimiam. Reitere-se, entretanto, que, para Adorno (1995a), tais mecanismos de opressão e de barbarização estão ligados a elementos objetivos, tanto de ordem social como política, contribuindo para o cerceamento da percepção. Quanto a tais mecanismos objetivos, salienta-se o seguinte:

A sociedade burguesa encontra-se subordinada de um modo universal à lei da troca, do "igual por igual" de cálculos que, por darem certo, não deixam resto algum. Conforme sua própria essência, a troca é atemporal, tal como a própria razão, assim como, de acordo com sua forma pura, as operações da matemática excluem o momento temporal. Nestes termos, [...] a memória, o tempo e a lembrança são liquidados pela própria sociedade burguesa em seu desenvolvimento (ADORNO, 1995a, p. 32-33).

Essa ausência de memória, conforme já se vem expondo, terá uma consequência funesta para a humanidade em geral, pois, ela conduzirá o homem a um processo profundo de "estranhamento e resignação pela 
'adaptação' à realidade vigente" (SCAREL, 2016, p. 131). A consequência disso no âmbito objetivo, isto é, no espaço onde reina a ordem econômica, é que a humanidade foi gradativamente se empobrecendo, porque ela foi renunciando a "[...] uma depois da outra todas as peças do patrimônio humano", penhorando-as "[...] muitas vezes a um centésimo de seu valor" e aceitando "[...] em troca a moeda do 'atual" (BENJAMIN, 1994, p. 119). Diante desse flagrante processo de danificação da subjetividade, em que se ela torna incapaz de exercer o tensionamento entre sujeito e objeto, entre particular e universal, entre teoria e práxis, não há, então, como não chegar a outro diagnóstico como o que lamentavelmente apresenta-se a seguir:

A subjetividade na modernidade apresenta-se cindida: uma esfera consciente e superficial, destinada à vivência, e uma esfera inconsciente, na qual apresentam-se as experiências. Essas não podem ser vividas como tais nem remetem a um saber acumulado; antes, só apresentam-se como lembranças (CROCHIK, 2010, p. 393).

Nesse sentido, reafirma-se que a degradação da cultura, como resultante desse processo do eclipsamento da razão, é catastrófica para as sociedades de uma forma ampla, porquanto as suas consequências não se estacam apenas no nível da objetificação das pessoas, conduzindo-as ao consumo desmedido, à competição, ao individualismo e à busca pelo prazer efêmero. Além disso, elas simultaneamente encaminham-se para um âmbito ainda mais complexo do que o universo objetivo, que é, consoante já se expôs, a fragilização da dimensão subjetiva, isto é, da dimensão psíquica dos indivíduos, que consiste no segundo elemento referido acima. Trata-se do contexto do Terceiro Reich, a partir do qual Adorno (1995a), com base na psicanálise, explicita com clareza os efeitos nocivos advindos da resistência ao cultivo da rememoração, passagem esta que se acredita ser uma das mais elucidativas para o entendimento das estruturas objetivas de assujeitamento dos indivíduos ao processo de dominação.

No referente ao lado subjetivo, [...] o nazismo insuflou desmesuradamente o narcisismo coletivo, ou, para falar simplesmente: o orgulho nacional. Os impulsos narcisistas dos indivíduos, aos quais o mundo endurecido prometia cada vez menos satisfação e que mesmo assim continuavam existindo ao mesmo tempo em que a civilização lhes oferecia tão pouco, encontraram uma satisfação substitutiva na identificação com o todo. Esse narcisismo coletivo foi gravemente danificado pela derrocada do regime nazista. Esses danos ocorreram no âmbito do meramente factual, sem que os indivíduos tenham se dado conta deles para assim elaborá-los. Este é o sentido sócio-psicológico correspondente ao discurso acerca do passado não dominado. 
Faltou inclusive aquele pânico que, de acordo com a teoria freudiana [...], se instala quando as identificações coletivas se esfacelam. Se atentarmos às indicações do grande psicólogo, isso permite apenas uma conclusão: que, no fundo, avolumando-se inconscientemente e por isto particularmente poderosas, aquelas identificações e o narcisismo coletivo não chegaram a ser destruídos, mas permanecem existindo (ADORNO, 1995a, p. 39-40).

Diante dessa demonstração, não é difícil imaginar por que toda sorte de atitudes extremistas multiplicaram-se em uma escala vertiginosa no contexto contemporâneo, por exemplo, o racismo, o preconceito, a dominação, a xenofobia, a banalização do mal, a exclusão social, etc., exigindo, por isso, um confronto esclarecedor tanto com referência aos fatores objetivos quanto com relação aos fatores subjetivos subjacentes a essa realidade alienante e contribuinte com a persistência da "fraqueza social do eu", tal como apregoam Adorno e Horkheimer na obra Dialética do Esclarecimento (1985).

Trata-se, como se pode observar, de um trabalho extremamente complexo, que impõe a necessidade de um exercício crítico em relação a essa tendência dos indivíduos de cultivarem instintos repressivos, freudianamente expressando, inclinando-se, assim, para a acentuação cada vez maior de mecanismos de desumanização mediante o culto da violência e da autodestruição. Daí a relevância da rememoração, pois compreende-se que ela se constitui em uma força extremamente eficaz no combate ao mito do esclarecimento e, também, a toda manifestação de violência, seja contra a vida humana, seja contra a natureza em geral. Daí insistir-se na crítica às condições atuais, com vistas à busca do entendimento desse processo de dominação cega que tem cerceado o trabalho do esclarecimento, convergindo, conforme já se afirmou, ao declínio da subjetividade, em virtude de a experiência encontrar-se empobrecida por causa de o sujeito estar incapacitado de exercitá-la, segundo a exposição acima de Benjamin (1994).

\section{A EXPERIÊNCIA DE AUSCHWITZ CONTRA A (DE) FORMAÇÃO HUMANA}

Um estudo mais aprofundado da obra adorniana leva à percepção irrefutável de que todo o seu arcabouço teórico é revestido de profunda coerência, principalmente em relação à luta contra os processos anticivilizatórios, portanto, contra a violência e a barbarização. Dessa forma, o texto "Educação após Auschwitz" alinha-se a essa perspectiva. O seu conteúdo postula a necessidade de a educação se transformar no fundamental veículo de combate à reedição de Auschwitz, pois ela configura-se na "[...] barbárie contra a qual se dirige toda a educação" (ADORNO, 1995a, p. 119). Para o frankfurtiano, somente uma análise profunda para além dos fatores que se 
ligam à dimensão objetiva poderia pôr em relevo as causas que conduziram ao horror causado por Auschwitz, as quais minaram senão todas, pelo menos grande parte das conquistas realizadas pelo conhecimento humano em prol da iluminação da razão.

$\mathrm{Na}$ concepção adorniana, era incompreensível como, por um lado, isto é, em termos objetivos, a civilização havia trilhado grandes avanços, entretanto, por outro, ou seja, referente à dimensão subjetiva, tinha retrocedido vertiginosamente. Conhecer, então, os elementos que se relacionavam a essa dimensão tornava-se condição imprescindível para a realização do confronto ao estado de barbarização no qual a sociedade alemã do seu tempo recaíra. "Se a barbárie encontra-se no próprio princípio civilizatório, então pretender se opor a isso tem algo de desesperador" (ADORNO, 1995a, p. 120).

Para empreender a análise de tal paradoxo, dois trabalhos antropológicos relativos à psicanálise freudiana irão constituir-se nos referenciais do filósofo. O primeiro deles denomina-se O mal-estar na cultura, produzido em 1930. Nesse texto, a tese de Freud (2010) é a de que a cultura, à medida que conquista o progresso cultural e econômico, fomenta um mal-estar nos indivíduos, obrigando-os a vivenciarem profundos conflitos e a renunciarem à satisfação dos seus desejos. Assim, "[...] o preço do progresso cultural é a perda da felicidade, pelo acréscimo do sentimento de culpa" (FREUD, 2010, p. 106). No segundo, intitulado de Psicologia das massas e análise do eu, escrito em 1921, Freud (2011), com base nos trabalhos do psicólogo social Le Bon (1841-1931), trata do comportamento do indivíduo no grupo. Para o pai da psicanálise, ao inserir-se em um grupo, pelo processo de identificação, o indivíduo tende a modificar-se, pois "[...] a identificação se empenha em configurar o próprio Eu à semelhança daquele tomado por 'modelo'" (FREUD, 2011, p. 62).

Esta breve síntese acerca do teor dos trabalhos de Freud dão uma dimensão bastante aproximada do motivo pelo qual Adorno (1995a) decidiuse pela apreensão das contribuições trazidas pela psicanálise, pois, na sua perspectiva, somente essa ciência das profundezas poderia perscrutar e desnudar as causas que possibilitaram emergir Auschwitz. Essa integração regressiva e repressiva tem ramificações profundas. Por isso, Adorno insiste na premência de se conhecer o caráter psicológico das pessoas responsáveis por esse infortúnio sob as justificativas mais vis, impondo, por isso, a exigência de se fazer a 
[...] inflexão em direção ao sujeito. É preciso reconhecer os mecanismos que tornam as pessoas capazes de cometer tais atos, é preciso revelar tais mecanismos a eles próprios, procurando impedir que se tornem novamente capazes de tais atos, na medida em que se desperta uma consciência geral acerca desses mecanismos. Os culpados não são os assassinados, nem mesmo naquele sentido caricato e sofista que ainda hoje seria do agrado de alguns. Culpados são unicamente os que, desprovidos de consciência, voltaram contra aqueles seu ódio e sua fúria agressiva. É necessário contrapor-se a uma tal ausência de consciência, é preciso evitar que as pessoas golpeiem para os lados sem refletir a respeito de si próprias (ADORNO, 1995 a, p. 121).

Quando não se reflete ou não se perquire sobre os efeitos que serão causados à relação sujeito e objeto, universal e particular, teoria e práxis, por causa da excessiva racionalização em detrimento da subjetividade, o sinistro resultado é este, isto é, a persistência de uma chaga aberta, que insiste em confrontar a capacidade humana de romper com esses comportamentos irracionais e frios em favor do esclarecimento por intermédio da "inflexão em direção ao sujeito", conforme exposto acima, ao seu contrário. Em outras palavras, é preciso que o sujeito reconheça, mediante o processo de reelaboração, de acordo com a perspectiva freudiana, a sua própria insuficiência, tanto em relação ao objeto como no tocante à práxis por ele idealizada, impedindo-o de realizar a experiência. “Onde a experiência é bloqueada ou simplesmente já não existe, a práxis é danificada e, por isso, ansiada, desfigurada, desesperadamente supervalorizada"(ADORNO, 1995b, p. 203-204). Esta é uma das razões pelas quais o sujeito pode facilmente perder a sua autoconsciência e reincidir na barbárie. "O sujeito egocêntrico é o homem indiferenciado, onipotente, narcisista e voltado para si em busca de uma identidade cristalizada, ilusória, prepotente" (ZANOLLA, 2015, p. 466).

Tem-se em vista que, a partir desse estado de engessamento da consciência, dissolve-se o eu e emerge a "personalidade autoritária", tendente às simplificações, principalmente dos processos históricos, nutrindo sentimentos maniqueístas e desenvolvendo atitudes de competitividade e de desprezo em relação ao outro. Essa inclinação ao dualismo pode ser confirmada com clareza, por exemplo, na longa passagem que se segue:

A história popular, e também a história tal como é tradicionalmente ensinada nas escolas, se ressente dessa tendência maniqueísta que evita os meios-tons e a complexidade: são propensas a reduzir a torrente dos acontecimentos humanos aos conflitos, e os conflitos a duelos, nós e eles, os atenienses e os espartanos, os romanos e os cartagineses. Decerto este é o motivo da enorme popularidade dos esportes espetaculares, como o futebol, o beisebol e o pugilismo, nos quais os contendores são dois times ou dois indivíduos, 
bem distintos e identificáveis, e no fim da partida haverá os derrotados e os vencedores. Se o resultado é o empate, o espectador se sente fraudado e desiludido: num nível mais ou menos inconsciente, ansiava por vencedores e perdedores, identificando-os respectivamente com os bons e os maus, porque são os bons que devem levar a melhor, senão o mundo estaria de pernas para o ar (LEVI, 2016, p. 27-28).

Esses exemplos comprovam por que se faz necessário voltar-se o pensamento para a desmistificação desses mitos narcisistas que desvirtuam a realidade e minam de forma implacável a memória do indivíduo, levando-o a rechaçar toda pretensão de luta contra a barbárie.

Por isso, Adorno (1995a) aponta não somente para a urgência, mas, sobretudo, para a necessidade de se empreender o embate tanto contra essa inclinação ao esquecimento e aos reducionismos como, ainda, ao seu ápice, isto é, contra o mundo reificado e imerso em uma profunda racionalização e uma pressão civilizatória inimaginável. “É possível falar da claustrofobia das pessoas no mundo administrado, um sentido de encontrar-se enclausurado, numa situação cada vez mais socializada, como uma rede densamente interconectada" (ADORNO, 1995a, p. 122).

Na sua visão, a resistência a esse processo histórico de violência generalizada passa a ser condição imprescindível, pois os fatores alienantes que fizeram com que viesse à tona a tragédia de Auschwitz não deixaram de existir, pelo contrário, consoante já se vem expondo, eles se acirraram cada vez mais, fragilizando, dessa forma, toda capacidade de confrontação às tendências anticivilizatórias. $E$, ao recorrer à ciência psicanalítica, Adorno (1995a) não somente detecta os fatores que conduziram os homens ao fascismo, mas, também, vislumbra a possiblidade de se evitar a repetição de Auschwitz. E, nesse sentido, formula um apelo para que se invista na educação como condição de possibilidade de realização de tal intento.

Quando falo de educação após Auschwitz, refiro-me a duas questões: primeiro, à educação infantil, sobretudo na primeira infância; e, além disto, ao esclarecimento geral, que produz um clima intelectual, cultural e social que não permite tal repetição; portanto, um clima em que os motivos que conduziram ao horror tornem-se de algum modo conscientes (ADORNO, 1995a, p. 123).

Mas por que a educação terá que ter como ponto de partida principalmente a primeira infância? Para Freud (2012), as imagens (imagos) boas ou más que o indivíduo carregará por toda sua existência são construídas, em especial, já nos primeiros anos de sua vida. No trecho a seguir, contido no texto "Sobre a psicologia do colegial", escrito em 1914 e posteriormente 
publicado em um volume comemorativo ao quinquagésimo aniversário de fundação do colégio onde Freud havia estudado, é possível captar o porquê de a educação ter de centrar-se, em especial, no início da vida da criança:

[...] as posturas afetivas em relação a outras pessoas, tão relevantes para a conduta posterior do indivíduo, são estabelecidas surpreendentemente cedo. Já nos primeiros seis anos de vida o pequeno ser humano tem assentados a natureza e o tom afetivo de suas relações com as pessoas do outro, e, do mesmo sexo; a partir de então pode desenvolvê-los e modificá-los em certas direções, mas não eliminá-los (FREUD, 2012, p. 420-421).

Atentar-se para essa perspectiva torna-se condição sine qua non para o fortalecimento da subjetividade, dotando o sujeito da capacidade de romper com as mutilações do espírito heterônomo, isto é, com o"[...] estado de menoridade, no sentido da idiotice sintética que hoje constatamos em todos os cantos e paragens" (ADORNO, 1995a, p. 177).

Por isso, o pensamento de Kant, apesar de se criticado por Adorno (1995b) por causa dos seus esquematismos, foi de grande relevância para o frankfurtiano, pois Kant (1996) possibilitou a compreensão de que a experiência só pode provir da unidade da consciência, ou seja, do estado de autonomia do sujeito diante do objeto. Ou melhor: "O'eu penso' tem que 'poder' acompanhar todas as minhas representações" (KANT, 1996, p. 121). Segundo apreende-se de Adorno (1995a), foi em virtude dessa ausência de unidade de consciência que os mecanismos que conduziram a Auschwitz passaram a existir, transformando o sentido de autoridade em autoritarismo e destruição, mediante o pacto com a democracia tão somente formal. Contra esse princípio destruidor do eu, Adorno expressa a necessidade do exercício da autonomia de pensamento e da autorreflexão crítica. "O único poder efetivo contra o princípio de Auschwitz seria autonomia, para usar a expressão kantiana; o poder para a reflexão, a autodeterminação, a não-participação" (ADORNO, 1995 a, p. 125).

É por isso que se tem em vista que somente um espírito autodeterminado resistiria aos mecanismos que conduzem aos estados adaptativos e alienantes, os quais levam os sujeitos a tornarem-se impermeáveis à experiência, reduzindo-se, tal como Poe (2017) descreve no seu conto "O homem da multidão", a autômatos, meros apêndices da multidão, que só reagem de forma mecânica e reflexa aos estímulos externos, porque esse homem da multidão, destituído de história e de memória, diluiu-se na massa e transformou-se na "frieza da mônada social", segundo Adorno (1995a, p. 134). Veja-se como esse homem que se desfaz na multidão é descrito ao final do conto por Poe (2017, p. 392): 
"Esse velho" - disse comigo, por fim - "é o tipo e o gênio do crime profundo. Recusa-se a estar só". É o homem da multidão. Será escusado segui-lo: nada mais saberei a seu respeito ou a respeito de seus atos. $O$ mais cruel coração do mundo é livro repulsivo que o Hortulus Animae, e talvez seja uma das mercês de Deus que es lässt sich nicht lesen (POE, 2017, p. 392).

Se, por um lado, essa descrição refere-se a uma ficção, por outro, não se pode negar que a literatura mostra a sua força, pois "O homem da multidão" guarda uma profunda simetria não somente com o homem moderno, mas, também, com o contemporâneo. Se a modernidade, por um lado, conseguiu avançar nos conhecimentos e na técnica, possibilitando mais conforto e qualidade de vida às pessoas, por outro, paradoxalmente, ela não atingiu o êxito pretendido. Afinal, quem é o "homem da multidão", senão aquele que fetichizou a técnica em detrimento da humanização, transformando-se, de acordo com Adorno (1995a), em uma "consciência coisificada"?

Os homens inclinam-se a considerar a técnica como sendo algo em si mesma, um fim em si mesmo, uma força própria, esquecendo que ela é a extensão do braço dos homens. Os meios - e a técnica é um conceito de meios dirigidos à autoconservação da espécie humana - são fetichizados, porque os fins - uma vida humana digna - encontram-se encobertos e desconectados da consciência das pessoas (ADORNO, 1995a, p. 132-133).

Dessa maneira, observa-se a partir desse autor que é justamente a ausência de consciência que se tornou responsável pelo fracasso de todas as tentativas de emancipação humana por meio do esclarecimento. Daí a pertinência da concepção kantiana de maioridade como possibilidade de superação do estado de menoridade em que as pessoas, de um modo geral, se encontram, em virtude da persistência dos mecanismos que reforçam a heteronomia, impedindo o exercício livre do pensamento, que advém, justamente, do esclarecimento.

Esclarecimento [Aufklärung] é a saída do homem de sua menoridade, da qual ele próprio é culpado. A menoridade é a incapacidade de fazer uso de seu entendimento sem a direção de outro indivíduo. O homem é o próprio culpado dessa menoridade se a causa dela não se encontra na falta de entendimento, mas na falta de decisão e coragem de servir-se de si mesmo sem a direção de outrem (KANT, 2005, p. 63-64).

Observa-se que, subjacente à ideia de maioridade nesta afirmação de Kant, encontra-se a perspectiva de liberdade. Para Kant (2005), a liberdade e o esclarecimento constituem-se condições imprescindíveis para o processo formativo que tem como objetivo a autonomia. É por isso que Adorno (1995a) 
recorre à ideia de educação e, por conseguinte, de formação postulada por ele, em face de a sua visão formativa se contrapor a todas as tendências adaptativas e reificantes, tais como os "preceitos e fórmulas" que, na sua visão, configuram-se nos "grilhões de uma perpétua menoridade" (KANT, 2005, p. 64). Deduz-se, a partir disso, que são exatamente essas correntes que arrastam os sujeitos em direção ao aprisionamento coletivo, conduzindo-os a resignarem-se à mera vivência, em razão de estarem impossibilitados de exercerem a experiência, já que "[...] foi rompido o nexo entre objeto e reflexão" (ADORNO, 1995a, p. 63).

Por isso, reitera-se que a ênfase atribuída por Adorno (1995a) a uma educação para o esclarecimento, isto é, para uma formação cultural (Bildung) e política não é apenas oportuna, mas, sobretudo, urgente, em virtude da existência dos inúmeros mecanismos subjetivos de potencialização dos extremismos, redundando em uma "ferida psíquica" continuamente aberta, tal como ocorreu com Auschwitz, impondo a necessidade de que se atente criticamente para eles, mediante uma educação política, consoante a afirmação que se segue:

[...] o centro de toda educação política deveria ser que Auschwitz não se repita. Isto só será possível na medida em que ela se ocupe da mais importante das questões sem receio de contrariar quaisquer potências. Para isto teria de se transformar em sociologia, informando acerca do jogo de forças localizado por trás da superfície das formas políticas. Seria preciso tratar criticamente um conceito tão respeitável como o da razão de Estado, para citar apenas um modelo: na medida em que colocamos o direito do Estado acima do de seus integrantes, o terror já passa a estar potencialmente presente (ADORNO, 1995a, p. 137).

Concluindo, diante de uma argumentação lúcida igual à que se encontra acima, a resistência torna-se inconteste. Pois, se a cultura tem se coadunado com os princípios que comungam com a violência, como imperativo único da ideologia do progresso, do individualismo e do esquecimento, contrapor-se a ela, também, passa a ser imperativo. $E$ isso somente se concebe mediante um processo formativo que, por um lado, negue a cultura da violência e da autoaniquilação e, por outro, afirme uma cultura que supere o esquecimento, por meio do enfrentamento ao horror instalado pelo silenciamento e, também, pela ideologia do falso compromisso, em favor de uma cultura que prime pela emancipação humana. "A capacidade para o medo e a capacidade para a felicidade são o mesmo: a abertura ilimitada, que chega à renúncia de si, para a experiência, na qual o que sucumbe se reencontra" (ADORNO, 1993, p. 175). Daí a premência 
da resignação contra o "espírito de frieza socializada pela ideologia da objetificação do espírito. Contra ela impõe-se a autorreflexão crítica, pois, segundo a'Dialética Negativa', o pensamento [...] precisa, para ser verdadeiro, hoje em todo caso pensar contra si mesmo" (ADORNO, 2009, p. 302). Entendese que esse princípio não é apenas congruente, mas, acima de tudo, atual.

\section{CULTURAL VIOLENCE AND THE FORMATIVE PROCESS TOWARDS EXPERIENCE: THOUGHTS REGARDING EDUCATION AFTER AUSCHWITZ}

ABSTRACT: This text, supported by a number of fundamentals of the Critical Theory of Society, particularly those stemming from Theodor Adorno, aims to develop, firstly, an anaylsis about violence in contemporary reality, and secondly and lastly, to discuss the relevance of experience driven towards human formation, trying to establish confrontation to the extremism that was enabled by the advent Auschwitz.

KEYWORDs: Contemporaneity. Violence. Education. Experience. Auschwitz.

LA CULTURA DE LA VIOLENCIA Y EL PROCESO FORMATIVO PARA LA EXPERIENCIA: NOTAS DE LA REFLEXIÓN SOBRE LA EDUCACIÓN DESPUÉS DE AUSCHWITZ

Resumen: Este texto, apoyándose en algunos fundamentos de la Teoría Crítica de la Sociedad, especialmente de Theodor Adorno, trata de elaborar, en primer lugar, una reflexión sobre la violencia en la realidad contemporánea y, en segundo y último lugar, discutir sobre la relevancia de la experiencia para la formación humana, con el fin de establecer la confrontación al extremismo posibilitado por el advenimiento de Auschwitz.

Palabras-Clave: Contemporaniedad. Violencia. Educación. Experiencia. Auschwitz.

\section{NOTAS:}

1 Segundo a psicanálise, a identificação consiste no"processo psicológico pelo qual um sujeito assimila um aspecto, uma propriedade, um atributo do outro e se transforma, total ou parcialmente, segundo o modelo desse outro. A personalidade constitui-se e diferencia-se por uma série de identificações" (LAPLANCHE; PONTALIS, 2001, p. 226). 
2 Entende-se que a elaboração psíquica é um conceito freudiano, utilizado, especialmente, para “[...] designar, em diversos contextos, o trabalho realizado pelo aparelho psíquico com o fim de dominar as excitações que chegam até ele e cuja acumulação corre o risco de ser patogênica. Este trabalho consiste em integrar as excitações no psiquismo e em estabelecer entre elas conexões associativas" (LAPLANCHE; PONTALIS, 2001, p. 143).

3 Conforme "Referências dos textos", contidas no anexo da obra Educação e emancipação (1995 $\mathrm{a}^{\prime}$ p. 187-188).

4 Idem nota 3.

5 Para aprofundamento nesse termo, consulte-se a obra Eclipse da razão (2000), escrita por Max Horkheimer.

60 termo dominação é empregado aqui na mesma perspectiva adotada por Weber (2012, p. 33), o qual o define como a“[...] probabilidade de encontrar obediência a uma ordem de determinado conteúdo, entre determinadas pessoas indicáveis".

7 Aqui está se tomando como referência o texto "A personalidade autoritária" (ADORNO et al, 2009), que tem como objeto de estudo os "tipos" que podem ser chamados de personalidades fascistas.

8 Crochík (2001), em um trabalho em que trata da concepção de mônada, afirma que, para Adorno, esse conceito vem se consubstanciando no "indivíduo burguês". E assim esclarece o seguinte: "A mônada se, de um lado, realiza o ideal de indivíduo do liberalismo, segundo o qual se cada um cuidar de seus interesses se fortalece a sociedade, de outro lado, serve como resistência à exacerbação do liberalismo: o fascismo. Os extremos se encontram: a sociedade reprodutiva e autonomizada dos interesses individuais condiz com o indivíduo alienado. Se no estudo das mônadas, Freud pôde localizar a dominação social, caberia utilizar esse conhecimento não para domesticar as pulsões ou empregá-las como a propaganda o faz, mas para libertar o indivíduo mediante a consciência que possa ter do que é feito com ele" (CROCHÍK, 2001, p. 23-24).

9 "Es lässt sich nicht lesen" - não pode ser lido.

\section{REFERÊNCIAS}

ADORNO, T. W. Educação e emancipação. Trad. Wolfgang Leo Maar. São Paulo: Paz e Terra, 1995a.

. Palavras e sinais: modelos, críticos 2. Trad. Maria Helena Ruschel. Sup. Álvaro Valls. Petrópolis: Vozes, 1995b.

Minima moralia: reflexões a partir da vida danificada. Trad. Luiz Eduardo Bicca. Rev. Guido de Almeida. 2. ed. São Paulo: Ática, 1993. (Série Temas Estudos filosóficos; v. 30). 
.Dialética negativa. Trad. Marco Antônio Casanova. Rev. Eduardo Soares Neves Silva. Rio de Janeiro: Zahar, 2009.

ADORNO, T. W.; HORKHEIMER, M. Temas básicos da sociologia. Trad. Álvaro Cabral. 2. ed. São Paulo: Cultrix, 1978.

. Dialética do esclarecimento: fragmentos filosóficos. Trad. Guido Antonio de Almeida. Rio de Janeiro: Jorge Zahar, 1985.

ADORNO, T. W. et al. Personalidade autoritária. In: Escritos sociológicos II. Madri: Akal, 2009. (Obra completa; v. 1).

BENJAMIN, W. Magia, técnica, arte e política. Trad. Sérgio Paulo Rouanet. 7. ed. São Paulo: Brasiliense, 1994. (Obras escolhidas; v. 1).

CROCHIK, J. L. A resistência e o conformismo da mônada psicológica. Psicologia e sociedade, São Paulo, v. 13, n. 2, p. 18-32, jul./dez. 2001.

A constituição do sujeito na contemporaneidade. Inter-Ação, Goiânia, v. 35, n. 2, p. 387-403, jul./dez. 2010.

FREUD, S. O mal-estar na civilização, novas conferências introdutórias à psicanálise e outros textos (1930-1936). Trad. Paulo César de Souza. São Paulo: Companhia das Letras, 2010. p. 13-122. (Obras completas; v. 18).

. Psicologia das massas e análise do eu e outros textos (1920-1923). Trad. Paulo César de Souza. São Paulo: Companhia das Letras, 2011. p. 13-113. (Obras completas; v. 15).

Sobre a psicologia do colegial. In: Sigmund Freud: totem e tabu - contribuição à história do movimento psicanalítico e outros textos (1912-1914). Trad. Paulo César de Souza. São Paulo: Companhia das Letras, 2012. p. 418-423. (Obras completas; v. 11). HORKHEIMER, M. Eclipse da razão. Trad. Sebastião Uchoa Leite. São Paulo: Centauro, 2000.

KANT, I. Crítica da razão pura. Trad. Valerio Rohden e Udo Baldur Moosburger. São Paulo: Nova Cultural, 1996. (Coleção Os pensadores).

. Resposta à pergunta: Que é "Esclarecimento"? (Aufklärung)? In: . Textos seletos. Trad. Floriano de Souza Fernandes. 3. ed. Petrópolis: Vozes, 2005. p. 63-71.

LAPLANCHE, J.; PONTALIS, J. B. Vocabulário da psicanálise. 4. ed. Trad. Pedro Tamen. São Paulo: Martins Fontes, 2001.

LEVI, P. Os afogados e os sobreviventes: os delitos, os castigos, as penas, as impunidades. Trad. Luiz Sérgio Henriques. 3. ed. São Paulo; Rio de Janeiro: Paz e Terra, 2016.

POE, E. A. O homem da multidão. In: . Histórias extraordinárias. Seleção, apres. e trad. José Paulo Paes. São Paulo: Companhia das Letras, 2017. p. 377-392. 
SCAREL, E. B. Dilemas inerentes ao potencial formativo entre conhecimento e dialética negativa. Goiânia, 2016. 158 f. Tese (Doutorado) - Faculdade de Educação, Universidade Federal de Goiás, 2016.

WEBER, M. Economia e sociedade: fundamentos da sociologia compreensiva. Trad. Regis Barbosa e Karen Elsabe. Rev. téc. Gabriel Cohn. 4. ed. Brasília: UnB, v. 1, 2012.

ZANOLLA, S. R. S. Dialética negativa e materialismo dialético: da subjetividade decomposta à objetividade pervertida. Kriterion, Belo Horizonte, n. 132, p. 451-471, dez. 2015.

Estelamaris Brant Scarel: Possui graduação em Direito pela Universidade Federal de Mato Grosso (1980), mestrado em Educação pela Pontifícia Universidade Católica de Goiás (2003) e doutorado em Educação pela Universidade Federal de Goiás. Atualmente é professora da Pontifícia Universidade Católica de Goiás e da Faculdade Araguaia. E-mail: estelamaris.brant@gmail.com 